\title{
Technology and Language: A Review of Students' Perceptions of Blog in some Selected English as a Second Language Writing Classes
}

\author{
Aisar Salihu Musa \\ Department of Arts and Humanities, Kano State Polytechnic, Nigeria \\ aisarresearch@yahoo.com
}

Published online: 27 December 2016

To cite this article: Aisar Salihu Musa. 2016. Technology and Language: A review of students' perceptions of blog in some selected English as a Second Language writing classes. Malaysian Journal of Distance Education 18(1): 1-12. http://dx.doi.org/10.21315/ mjde2016.18.1.1

To link to this article: http://dx.doi.org/10.21315/mjde2016.18.1.1

\begin{abstract}
Emergence and integration of Web 2.0 technologies in the students' learning process brought a pedagogical paradigm shift in many of today's classrooms. Unfortunately, many educators (including the teachers of Teaching English as a Second Language [TESL]) are either unaware or skeptical about this new culture. Students taking English as a Second Language (ESL) are still having a problem in writing an error-free assignment or test. Fortunately, blog (a computer-mediated technology) brought a hope and serves as a help to both tutors and learners by being a teaching and learning tool that can promote the students' English language writing skills. Using systematic review, this paper aims to examine the students' perceptions of blog in some selected ESL writing classes. The purpose is to introduce blog and create awareness to both educators and students about its application and benefits in today's educational institutions, especially ESL writing classes. One research question was developed and two academic social network platforms were explored and about 41 relevant journal articles were found. After using inclusion and exclusion criteria, only five articles met the criteria of this review. Findings revealed that though blog was still new to many respondents but their perceptions of it (blog), was positive.
\end{abstract}

Keywords: Web 2.0, blog, English as a Second Language (ESL) writing classes 


\section{Introduction}

Nur Ehsan et al. (2013) argued that, the conventional method of teaching ESL is still facing challenges of 1st language interference and becoming unmotivating especially when students are limited to in-class activities. However, the emergence and integration of Web 2.0 technologies as a learning or teaching tool is becoming popular amidst criticisms resulting from technological backward in some places. Social networks such as Facebook, Wikis, and Blogs that are designed for social interactions are forcing their ways into educational institutions, and especially in the area of Foreign Language (Ducate and Lomicka, 2008). These new pedagogical instruments have transformed learners from passive into active players in the learning process. According to Nazrah, Hafizah and Azizah (2010), nowadays, in ESL classrooms, as a result of advancement in Information Communication Technology (ICT), attention is being shifted from teachercentred to student-centred learning. Similarly, learning ESL through technology in this 21 st century is becoming part of the students' life. Therefore, time has come for educators to integrate these internet-based tools in the students' learning process (Ahluwalia, Gupta, and Aggarwal, 2011; Chapelle, 2005). As these computer-assisted language learning tools are many, weblog (popularly known as blog) is receiving attention and becoming popular in ESL classrooms.

Writing is one of the critical learning aspects that ESL students are struggling with. This is because of the mental and behavioral nervousness. Students also have to follow the process of planning, drafting, revising, editing, publishing and receiving feedback (Abdurrahman, 2011; Arslan and Kizil, 2010). Blog is seen as a technological learning tool that is useful and capable of enhancing learner's writing performance (Arslan and Kizil, 2010). This development of blogs in language learning classes has also led to the emergence of another area of research which Ward (2004) theorised as 'blog assisted learning language' which is now called BALL. Although the studies on blog's effects on students' learning ability (Ahluwalia, Gupta and Aggarwal, 2011) but are growing on a daily basis (Abdurrahman, 2011). The aim of this systematic review is to provide an overview of the concept of blog (history, meaning, and features) and the students' perceptions of blog usage in some selected ESL/EFL writing classes. This will help teachers and students who are not aware, naive or reluctant toward it. Finally, this 
article will provide suggestions for future effective application of blogs in ESL writing classes.

\section{Historical Background of Weblog}

Winer (as cited in Campbell, 2003) claimed that people have been using weblogs since the origin of World Wide Web. However, Ward (2004) disputed that the act of blogging started around 1993 as a Forum for the National Center for Supper Computing Applications (NCSA). Many scholars (Anh and Ho, 2009; Hashemi and Najafi, 2011; Zhang, 2012,) attribute that it was John Berger who firstly coined the term 'weblog' in 1997. Later, in 1999, a web designer, Peter Merholz 'jokingly' in his website www. peterme.com breaks the word 'weblog' into 'we blog'. Similarly, according to Quible (2005), blog, blogging and blogger became prominent in 1999. Stovall (2012) traced that blogs started primarily as personal diaries, but later used for many purposes. According to Martindale and Wiley (2012), when blog first appeared in 1997, the use of the internet was largely not for profit making. The perceive ease and usefulness of weblogs allow their users to grow tremendously and penetrate into commercial, journalistic, and educational institutions (Campbell 2003).

\section{What is a Blog?}

Defining the term weblog is somewhat problematic (Martindale and Wiley, 2012). This is because the term (weblog or blog) has attracted the attention of many scholars, researchers, and commentators from diverse academic discipline which includes: computer, technology, language, science, communication and journalism. Therefore, the genre (blog) has been defined differently according to the connection and experience of the person. Bolt et al. (2007:2) discovered that 'during the 1990s, weblogs became a popular means of communication on the internet. This prompted journalists, communication scholars, and linguists to offer a variety of definitions'. Ward (2004) buttressed the definition of blog, as an updated website. People keep upgrading its original definition given by Berger.

Literally, blog or weblog can be used as a noun or a verb (Anh and Ho, 2009). According to Goldstein (2009) blog is a shortening form of 'weblog', an amalgam of 'web' and 'log'. In another word, it is a contraction of web 
and log. Campbell (2003) sees weblog as an online diary that is regularly updated by people using their own words, thoughts, and ideas. A unanimous cyber definition of blog according to Ward (2004) is that, blog is a website that is constantly updated and arranged sequentially according to time, date and in reverse order from new entry backward. In these definitions, web and blog are found to be in a constant relationship. Jones (2006) explains that weblog is regarded as blog because people enter what they write into the web. Technically, Attawutikul, Wiwitkunkasem and Smith (2013) explained that there is a connection between web and blog because it is part of the internet group based applications that build on the ideological and technological foundations of web 2.0 version and that allow the creation of user-generated content. Bolt et al. (2007) gave a very insightful and encompassing definition of blog:

A weblog, commonly referred to as a blog, is defined as an identifiable website that functions as a communication medium so that authors and readers may share information, opinions and commentary in an asynchronous and accessible self-published forum. The weblogger or author of the site, researches, gathers, and filters online information by frequently providing updates in a chronological and archivable format. The blog user or reader is provided with the opportunity to publicly voice his or her opinions through online comments and also offered related web links for additional information.

Blog is very easy to operate as Zaini, Kemboja and Supyan (2011) and Noytim (2010) corroborated that, blog is a free-user-friendly device that is easily opened, modified, used, maintained and regularly updated. Since blog is simple and easy to use and can be created in five minutes Flatley (as cited in Bolt et al., 2007), there are many free blogging service providers available online for users such as www.blogger.com, www.wordpress.com, www.livejournal.com, and www.xanga.com.

\section{Features and Classification of Weblogs}

Although blog has been defined as a website, journal or a diary that bloggers use to write, publish and share their ideas with digital citizens, its dynamic nature makes it different with static websites and other web 2.0 technologies 
in creation, format, features and functions. Nevertheless, among these newcommunicative-learning instruments, blog shares similarities with chat rooms, discussion boards, forums and emails (Campbell, 2003; Moon and Lim, 2013). Blog as an asynchronous communicative, interactive computermediated-communication allows learning to take place between teachers and their students without time, and space limitation. Teachers give out instructions and assess their students' works through their blogs without necessarily meeting in a classroom and the same goes to students use their peers in conducting assignments and interactions. Blog has some distinctive features which according to Martindale and Wiley (2012) and Moon and Lim (2013), a typical blog should have:

1. Ownership description.

2. Time and date of entries.

3. Entries arranged in reverse sequential order in the form of headlines.

4. Archive of previous blog entries.

5. A 'blog roll' - a list of other blogs in contact with the current blog.

6. These distinctive qualities of blogs attract the attention of many people toward them. For this, according to Zhang (2012), there are six main categories of weblogs: (1) the basic blog, (2) micro-blog, (3) family blog, (4) collaborative blog, (5) commercial, corporate or advertising blog, and (6) others include: journal blog and diary blog; knowledge $\log$, K log, K blog, news blog, pundit blog, fotoblog, video blog, audio blog etc. As blogs establish their place in many of today's classrooms, ESL/EFL classrooms join the race as well.

\section{Blog Usage in ESL Classrooms}

The use of weblogs in ESL/EFL classrooms to promote learners' writing skills continue to grow and capture the attention of L2 instructors (Abdurrahman, 2011; Noytim, 2010; Zaini, Kemboja and Supyan, 2011). These language instructors are attracted to blogs as pedagogically sound instruments because of their interactive and collaborative nature (Zaini, Kemboja and Supyan, 2011; Ducate and Lomicka, 2008). Basically, there are main three forms of blogs in ESL classrooms: (1) tutor blog, (2) learner blog, and (3) class blog (Campbell, 2003). These blogs are majorly used in ESL reading or writing classes. 
Table 1 Type and functions of blogs

\begin{tabular}{ll}
\hline Types of blog & Functions of blog \\
\hline Tutor blog & - Own and manage by the instructor. \\
& - An information unit for class activities. \\
& - Explore other English or course related websites. \\
& - Oromote online interaction between members. \\
Learner blog & - Use for reading and writing purposes. \\
& - A dairy and channel for submitting assignments. \\
& - A forum for discussion and brainstorming. \\
Class blog & Own and operate by members of the class. \\
& - A tool for posting and discussing issues on the list. \\
& - An interactive space between teachers, students, and colleagues. \\
\hline
\end{tabular}

\section{Method}

A systematic review was employed in this study for data collection. Systematic review aimed at answering specific questions on the topic of interest through a rigorous process of synthesizing and summarizing of the existing literature. This systematic review is only based on the online articles published on the internet between July 2015 to December 2015. The main question of this review was; what is the students' perception of blog usage in ESL writing classes? The keywords used in search of the relevant articles were: technology in language learning, social media in learning a language, students' perceptions of blog and the usage of blog in ESL writing class. The following were the phases followed in the conduct of this review:

\section{Identification of relevant article}

Two academic social network platforms were searched on the internet: Mendeley $(n=32)$ and ReseachGate $(n=9)$. All the abstracts of the revealed articles were read and looked for the relevancy to the study being investigated. 


\section{Inclusion and Exclusion Criteria}

Before searching for the relevant article began, the researcher set the following criteria in which an article was selected:

1. Theme: Trend on blog studies in education institutions

2. Research design: Survey (qualitative, quantitative or mixed)

3. Research focus: Only studies on perception (opinion)

4. Respondents: Only higher education institution students

5. Scope: Only ESL countries

6. Class: Only ESL writing classes

7. Article: Full article and only empirical

\section{Critical Analysis}

After gathered all the 41 articles from the searched platforms, all the articles were carefully and rigorously read and then subjected to a self-devised critical review based on the framework adopted in this study. The purpose of this examination is to evaluate and weed out irrelevant articles.

\section{Findings and Discussion}

By using the keywords 'search', a number of 41 articles were successfully obtained from the two academic social network platforms. However, upon using vetting system through inclusion and exclusion criteria, 11 articles were conceptual, 16 were not published in Open Access journals; only their abstracts were available, seven articles were from countries where English is the first language, two studies were purely experimental. As such, only five articles fully met the criteria of the study and therefore were considered relevant and used in the analysis and discussion of this systematic review as presented below.

\section{Relevant Articles}

In India, Ahluwalia, Gupta and Aggarwal (2011) conducted a longitudinal survey on students' perceptions and experiences of blogging in learning the English language. Forty two Engineering students were sampled to create, write, and publish their assignments using blog. Mixed research 
method was used as data were collected using online survey and interview. Results revealed that none of the participants had a blog before the study, but majority $(66.6 \%)$ responded positively that they liked posting their assignments through blog as it improved their writing skills and become an effective medium for self-expression. However, a follow up survey revealed that very few (16) ever visited their blogs again as they received no pressure from their lecturers or any additional grade. A similar result was obtained in Hashemi and Najafi (2011) as the majority of the respondents knew nothing about blog before the study.

In Iran, Hashemi and Najafi (2011) investigated the students' reactions and feedback on the usage of blog in an English writing class. Thirty undergraduate students were selected and asked to create their personal blog and write an article of 150 words and post it on their blogs weekly. Survey method was used and the findings indicated that, before the study, $80 \%$ of the respondents never heard the word blog, but later, they all enjoyed using blog and seven of them claimed to have improved their writing skills as a result of blogging. Participants' attitude towards blogging in this study was disappointing when compared to the results obtained in Aljumah (2012) and Nur Ehsan et al. (2013).

In Saudi Arabia, Aljumah (2012) explored the students' perceptions and attitude towards blog in an English writing course. Thirty five undergraduate English major students were asked to create their personal blogs and write an article of 150 words. The study lasted for 14 weeks and data was gathered through mixed research method. All the respondents perceived that it was a good idea using blog as a tool of writing and the majority (91\%) claimed to write and express themselves better through blogging as it assisted them to improve their writing skills. This result contributes to the findings of Nur Ehsan et al. (2013).

Lin, Groom and Lin (2013) analysed the role of Blog Assisted Learning Language (BALL) in Taiwanese ESL writing class. The researchers intended to find out what students think about blog as a learning tool and how they evaluate the effectiveness of blog in their writing assignments. 21 first grade English major students participated in the study. Tutor and learners' blogs were concurrently used. Unlike in Faroutan et al.'s study, in this study, the class took place in a computer laboratory and met only 
once in a week. The course lasted for two semesters (37 weeks) and aimed to develop students' writing skills through English essay writing. Students were asked to post 17 entries and invite their friends to comment on their blogs. Finally, all students were invited for 30 minutes in-depth interview and data was analysed using phenomenological qualitative analysis. Results indicated that interviewees felt that blogging is a new way to practice writing, submitting assignments, and had positively improved their writing skills. The same finding was acknowledged and Zhou (2015). Like in Faroutan et al. (2013), few students were worried to make mistake and receive critical comments from the online audience. Contrary to Zhang et al. (2014), there was no big difference in students' motivation in this study.

In Malaysia, Nur Ehsan et al. (2013) surveyed the students' perceptions and attitude of blogging in an ESL writing class. The objective of the study was to find out the usage of blog as a tool of writing in an English writing classroom. Thirty three undergraduate (TESL) students taking Technology in Education were asked to create their personal blogs and write about their experience during learning the course. Online questionnaire in fourpoint Likert-scale questioning format was sent to the respondents through surveymonkey.com. The findings of the study revealed that participants perceived blog to be an effective tool of writing and editing as majority of them $(57.6 \%)$ posted more than 12 posts in a month. This result was better than what was obtained in Hashemi and Najafi (2011) as majority posted fewer than 3-5 articles. Similarly, majority (54.5\%) enjoyed writing through blog as it enhanced their writing skills and made them to be aware of academic writing style and careful in constructing sentences and paragraphs.

\section{Conclusion}

Integration of computer-assisted tools such as blogs in the students' learning processes in ESL writing classes is gaining currency in many places as this paper discovered. Therefore, EFL/ESL educators and learners need to embrace these modern technologies as they help in enhancing the students' writing skills which have been an aged lingering problem which ESL educators have been battling to address. These instructors have to reconsider their attitude and disbelief (skepticism) towards these new technologies as there are playing a vital role in the current pedagogical practice by making things easier to both learners and tutors. In some countries like Malaysia, 
government is advocating for change in its curriculum by integrating these internet-assisted teaching and learning tools in its institutions of learning. This shows how important, powerful and effective these cutting-edge technologies (Ahluwalia, Gupta, and Aggarwal, 2011) are becoming. The three forms of blogs; tutor, learner, and class introduce a new method of teaching and learning which is motivating, collaborative, appealing, and beyond classroom activities. By blogging, students have the opportunity to practice and develop their writing skills, learn new vocabularies, phrases and in turn correct their grammatical mistakes and spelling through comments from their peers and teachers. In this new technique, teacherstudent interaction is positive and students become confident to write carefully. However, according to Blackmore-Squires (as cited in Nazrah, Hafizah and Azizah, 2010), students with computer-phobia, will find it very difficult to improve their writing skills through blogging. Finally, the use of blog in ESL writing classrooms is not a replacement of 'talk and chalk' method (Ahluwalia, Gupta and Aggarwal, 2011) or an impeccable solution to curtail the menace of poor writing skills of ESL students, but rather a new resourceful pedagogical shift that is yielding a positive result to both learners and instructors

\section{Challenges and Further Studies}

After systematically reviewing studies on students' perceptions of the usage of blog in some ESL writing classes, findings indicate that this new method of computer-assisted learning and teaching technique comes with some challenges that educators and students are surviving with. First, lack of or inadequate knowledge of blog and its benefits in ESL classrooms. Second, type of blogging software to be used. Third, teacher's limited attention to students' blogs. Fourth, inadequate facilities in terms of computer and internet services. Therefore, for effective use of blogs in ESL writing classes, the above problems should be taken into consideration. More and more studies should be investigated on blog usage in ESL classrooms (Nazrah, Hafizah and Azizah, 2010; Ahluwalia, Gupta and Aggarwal, 2011). For future studies, attention should be geared towards the impact of teacher's feedback on students' cognitive writing process, blog among major and non-major English students, and longitudinal studies on students' attitude after participating in a blogging study as did in Ahluwalia, Gupta and Aggarwal, 2011. 


\section{References}

Abdurrahman, M. B. 2011. Using blogs to facilitate ESL writing in a tertiary institutions. Masters diss, University Malaya, Malaysia.

Ahluwalia, G., D. Gupta and D. Aggarwal. 2011. The use of blogs in English language learning: A study of student perceptions. Bogota Colombia 13(2): 29-41.

Aljumah, F. H. 2012. Saudi learner perceptions and attitudes towards the use of blogs in teaching English writing course for EFL Majors at Qassim University. English Language Teaching 5(1): 100-116.

Anh, G. and L. Ho. 2009. Blogging and Viatnamese language teaching and language learning. Electronic Journal of Foreign Language Teaching 8(2): 385-398.

Arslan, R. Ş. and A. Şahin-Kizil. 2010. How can the use of blog software facilitate the writing process of English language learners? Computer Assisted Language Learning 23(3): 183-197. https://doi.org/10.1080/09588221.2010.486575

Attawutikul, S., K. Wiwitkunkasem and D. R. Smith. 2013. Use of weblogs to enhance group learning and design creativity amongst students at a Thai University. Journal of Innovations in Education and Teaching International 51(4): 379-388.

Bolt, J., J. L. Talbert, G. Lawson-Borders, G. D. Crossman, M. A. Garmon and A. M. Limperos. 2007. Blogs in communication research: Creating a definition and a content analysis of weblogs. Paper presented at the annual meeting of the NCA 93 ${ }^{\text {rd }}$ Annual Convention, Chicago, IL. http://citation.allacademic.com/meta/ p194192_index.html.

Campbell, A. P. 2003. Weblogs for use with ESL classes. http://iteslj.org/Techniques/ Campbell-Weblogs.html.

Chapelle, C. A. 2005. Computer applications in second language acquisition: Foundations for teaching, testing and research. UK, Cambridge: Cambridge University Press.

Ducate, L. and L. Lomicka. 2008. Adventures in the blogosphere: from blog readers to blog writers. Computer Assisted Language Learning 21(1): 9-28. https://doi. org/10.1080/09588220701865474

Goldstein, A. M. 2009. Blogging evolution. Education and Outreach 2(3): 548-559. https://doi.org/10.1007/s12052-009-0149-9

Hashemi, M. and V. Najafi. 2011. Using blogs in English language writing classes. International Journal of Academic Research 3(4): 599-604.

Jones, S. G. 2006. Blogging and ESL Writing: A case study of how students responded to the use of weblogs as a pedagogical tool for the writing process approach in a community college ESL writing class. PhD diss., University of Texas, USA.

Lin, M. H., N. Groom and C. Y. Lin. 2013. Blog-assisted learning in the ESL writing classroom: A phenomenological analysis. Educational Technology and Society 16(3): 130-139.

Martindale, T. and D. A. Wiley. 2012. Using weblogs in scholarship and teaching. Journal of Tech Trends 49(2): 55-61. https://doi.org/10.1007/BF02773972

Maryam Foroutan, Nooreen Noordin and Mohd Sahandri Gani bin Hamzah. 2013. Weblog Promotes ESL Learners' Writing Autonomy. Journal of Language Teaching \& Research 4(5): 994-1002. https://doi.org/10.4304/jltr.4.5.994-1002 
Moon, D. and D. K. Lim. 2013. Using weblogs in foreign language classrooms: Possibilities and challenges. International Journal of Software Engineering and its Applications 7(5): 121-128. https://doi.org/10.14257/ijseia.2013.7.5.12

Nazrah Abu Bakar, Hafizah Latif and Azizah Ya'acob. 2010. ESL students' feedback on the use of blogs for language learning. 3L: Language, Linguistics, Literature, Southeast Asian Journal of English Language Studies. 16(1): 120-141.

Noytim, U. 2010. Weblogs enhancing EFL students' English language learning. Procedia Social and Behavioral Sciences 2(2): 1127-1132. https://doi.org/10.1016/j. sbspro.2010.03.159

Nur Ehsan Mohd Said, Melor Yunus, L. K. Doring, Alfian Asmi, Farah Aqilah and L. Kwan. 2013. Blogging to enhance writing skills: A survey of students' perception and attitude. Asian Social Science 9(16): 95-101.

Quible, Z. K. 2005. Blogs and written business communication courses: A perfect union. Journal of Education for Business 80(6): 327-332. https://doi.org/10.3200/ JOEB.80.6.327-332

Stovall, J. G. 2012. Writing for the mass media. 8th edition. Upper Saddle River: Pearson Education, Inc.

Ward, J. M. 2004. Blog assisted language learning (BALL): Push button publishing for the pupils. TEFL Web Journal 3(1): 1-16.

Zaini Amir, Kemboja Ismail and Supyan Hussin. 2011. Blogs in language learning: Maximizing students' collaborative writing. Procedia Social and Behavioral Sciences 18(2011): 537-543. https://doi.org/10.1016/j.sbspro.2011.05.079

Zhang H., W. Song, S. Shen and R. Huang. 2014. The effects of blog-mediated peer feedback on learners' motivation, collaboration, and course satisfaction in a second language writing course. Australasian Journal of Educational Technology 30(6). https://doi.org/10.14742/ajet.860

Zhang, Z. 2012. Studies on college english writing teaching based on blog. http://www.atlantis-press.com/publications/aisr/citcs-12/index _ citcs-12.html?http\%3 A//www.atlantis-press.com/php/paper-details. php\%3Ffrom\%3Dviewarticles\%26id\%3D3157.

Zhou, H. 2015. An Empirical Study of Blog-assisted EFL process writing: Evidence from Chinese non-English majors. Journal of Language Teaching and Research 6(1): 189-195. https://doi.org/10.17507/jltr.0601.23 